\title{
Prevention of Preterm Labour: 2011 Update on Tocolysis
}

\author{
C. Hubinont and F. Debieve \\ Department of Obstetrics, Saint-Luc University Hospital, 10 Avenue Hippocrate, 1200 Bruxelles, Belgium
}

Correspondence should be addressed to C. Hubinont, corinne.hubinont@uclouvain.be

Received 3 May 2011; Accepted 27 September 2011

Academic Editor: Yves Jacquemyn

Copyright ( $\odot 2011$ C. Hubinont and F. Debieve. This is an open access article distributed under the Creative Commons Attribution License, which permits unrestricted use, distribution, and reproduction in any medium, provided the original work is properly cited.

The aim of this paper is to review available data about drugs for preventing preterm labour. Tocolytic therapy includes $\beta$ adrenergic receptor agonists, NO donors, magnesium sulphate, prostaglandin-synthase inhibitors, oxytocin receptor antagonists, calcium-channel blockers, progesterone, 17- $\alpha$-hydroxyprogesterone caproate, and antibiotics. Their specific effects on myometrial contractility, their safety, their efficiency, and side effects profile for the mother and the fetus are presented. The main question of why and for what reasons tocolysis should be administrated is discussed.

\section{Introduction}

Preterm delivery is defined by a birth occurring before 37 weeks of gestation or before 259 days from the last menstrual period. Prematurity is multifactorial and its incidence has increased during the last decade in most occidental countries, probably due to increased risk factors responsible for elective prematurity [1-3].

The mechanisms for preterm labour are still unclear. It could be associated either with a premature activation of the physiological contracting process or with a pathological factor responsible for uterine contractions, leading to preterm delivery [1-3].

Among identified pathways for preterm labour, there are uterine overdistension due to multiple pregnancies or polyhydramnios, placental ischaemia, cervical disease, immunologic and allergic phenomena, decidual or retroplacental haemorrhage, fetal endocrine activation intrauterine infections, and inflammatory processes. Elective prematurity due to maternal or foetal conditions is becoming a significant cause [1-4].

Tocolytic drugs have been available for several decades but their actions are directed toward the effects and not the causes of preterm labour $[1,3,5]$.

Therapeutic strategies available in the literature for stopping preterm labour are discussed in this paper. Their efficacy depend on an early and accurate diagnosis of the condition, the fetal fibronectin, and cervical length ultrasonography [2] .
Drugs safety and side effect profile is a major concern not only for the pregnant women but also for the foetus [4-6]. In some clinical conditions such as abruptio and chorioamnionitis, inhibition of uterine contractions and birth delay may be more harmful in terms of outcome and should be avoided [2,3]. Another concern is the administration route and the optimal range of gestational age for these treatments [5].

Tocolysis aims not only to inhibit uterine contractions but also to allow a safe transfer of the pregnant patient to a tertiary care centre. It gives the opportunity to administrate corticosteroids for preventing neonatal risks associated with prematurity [5-7].

\section{Mechanisms of Tocolysis}

Myometrial contractility is a complex process based on myocytes function. It involves the presence of hormonal receptors, ions channels, intercell gap junctions, and regulatory proteins such as oxytocin, endothelin, tachykinin, and angiotensin $[8,9]$. The increase of intracellular calcium concentration is essential for the uterine smooth muscle contraction [9].

As shown on Figure 1, uterine relaxation may be obtained by interfering with an intracellular messenger responsible for contractile proteins effects: $\beta$ adrenergic receptor agonists, nitric oxide (NO) donors, magnesium 


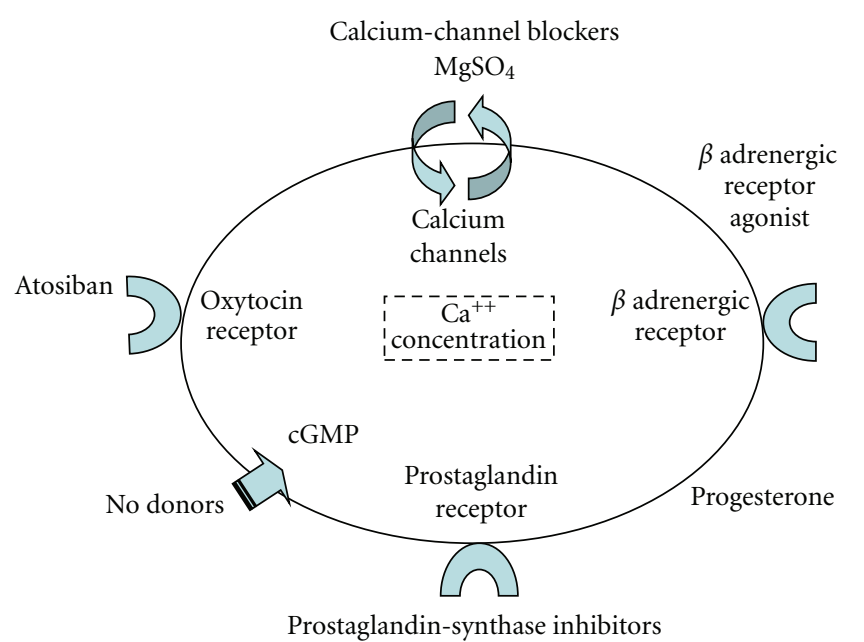

FIGURE 1: Mechanisms of action for tocolytics.

sulphate and calcium channel blockers are tocolytic drugs aiming to this $[1,2,6,9]$. Another pathway involves the inhibition of contracting factors synthesis or effect. Atosiban, an oxytocin receptor antagonist and prostaglandin-synthetase inhibitors have this effect by interfering with endogenous myometrial stimulators $[1,2,6,9]$.

\section{Types of Tocolytic Treatment}

3.1. $\beta$ Adrenergic Receptor Agonists. Selective $\beta 2$ agonists such as ritodrine and salbutamol have been used in clinical practice for preterm labour since the 1980s. These drugs impair intracellular cyclic AMP concentration and facilitate myometrial relaxation $[9,10]$. Randomized controlled studies and meta-analysis reported that these agents were more efficient than placebo for delaying preterm birth for two days. Unfortunately, no benefit for long-term (tocolytic effect restricted to 7 days) and perinatal mortality and morbidity rate was found $[5,10,11]$. Moreover, even with selective $\beta 2$ adrenergic receptor agonists, there are significant maternal side effects reported such as tachycardia, dyspnoea, hypokalemia, hyperglycemia, and chest pain $[5,6,9-12]$. In conclusion, despite their efficiency, $\beta 2$ agonists' safety profile is a real concern responsible for therapy discontinuation and choosing alternative tocolytic drugs.

3.2. NO Donors. NO is a powerful vasodilator synthesized during an amino acid oxidation process catalysed by NO synthase. It is present in myometrial cells and increases cGMP content by interaction with guanylyl cyclase. There is a specific link between $\mathrm{NO}$ production and uterine relaxation $[8,9]$.

Transdermal nitroglycerin administration has been used in preterm labour but only in small series. It was associated to a better tocolytic effect than placebo on delaying delivery for two days. Its effect was similar to ritodrine [2-5]. As there is no large randomized studies available, NO is not used in clinical routine.
3.3. Magnesium Sulphate. The relaxant effect of Magnesium sulphate in vitro and in vivo on human uterine contractility has been widely reported. As magnesium is a calcium antagonist, it decreases calcium intracellular concentration and inhibits contraction process $[2,4,9]$. However, in 2002, a meta-analysis based on 881 patients did not evidence any benefit of Magnesium sulphate administration over placebo use in preterm labour [13]. As the drug is crossing the placenta, there were concerns about fetal safety. An increased risk of perinatal death and neonatal adverse effects including neurological and metabolic disorders were reported in some trials using Magnesium sulphate treatment at high dosage [6, 13]. It can also affect maternal neuromuscular system. Over a serum concentration of $9 \mathrm{mg} / \mathrm{dL}$, there is a high toxicity risk resulting in respiratory depression and disappearance of reflexes. There is no evidence any more to recommend this drug as a first-line tocolytic agent $[2,6,13,14]$.

However, when administered prophylactically at low dose, it was reported to have a neonatal neuroprotective effect in a randomized multicentre trial [15] but this effect should be confirmed in the next future on large randomised controlled studies [16].

3.4. Prostaglandin-Synthase Inhibitors. Prostaglandin-synthase or cyclooxygenase (COX) isoforms COX-1 and -2 are essential enzymes for converting arachidonic acid to prostaglandins. Prostaglandins are well-known uterine contraction inducer by enhancing myometrial gap junction and increasing intracellular calcium concentration $[2,4,5$, 9]. Indomethacin, a nonspecific COX inhibitor, has been reported in studies and in a recent meta-analysis to be an efficient tocolytic drug compared to placebo, significantly delaying preterm delivery [11]. It can be administrated rectally or orally. Its use should be restricted in duration and limited to pregnancies below 32 weeks because of fetal ductus arteriosus closure risk and decreased urine production responsible for oligohydramnios $[3,5,6,17]$. These treatments also have maternal side effects including gastric ulcer or asthma recurrence $[3,5,6]$. COX-2 inhibitors such as nimesulide or rofecoxib have been studied in animal but not yet in humans and are not actually recommended for preventing preterm labour in clinical practice [18]. In conclusion, indomethacin is an efficient tocolytic drug with no serious adverse drug reaction and is indicated for shortterm effect during the second trimester of pregnancy.

3.5. Oxytocin Receptor Antagonists. These agents are in competition with the myometrial and decidual oxytocin receptors. The only drug used in clinical practice is atosiban. It blocks in a reversive manner the intracytoplasmic calcium release associated with contractions and downregulates prostaglandin synthesis [2,9]. A first multicentric randomised trial comparing atosiban and ritodrine demonstrated a similar tocolytic effect but fewer adverse effects with atosiban $[4,6]$. A meta-analysis published in 2005 reported no benefit in terms of preterm delivery rate and neonatal outcome in 1695 patients treated either by atosiban or placebo [19]. This study was responsible for the FDA nonapproval of atosiban in the USA. However, in Europe, many studies were carried out and did not confirm it. 
Atosiban is widely used in clinical practice because of its low side effects profile $[5,6]$. A german meta-analysis based on 6 randomised trials, among them 3 double blind studies, confirmed a similar tocolytic action for atosiban and $\beta$ adrenergic receptor agonists. A significantly low incidence of adverse effects is reported. Moreover, a lower cost saving in terms of hospital length and extra tests for excluding morbidity causes is found for the atosiban treated patients when compared to continuous fenoterol administration controls [12]. In conclusion, atosiban seems to be an adequate therapeutic choice for effective tocolysis with a low maternal and fetal adverse effects profile.

3.6. Calcium-Channel Blockers. These agents are interfering with the calcium ions transfer through the myometrial cell membrane. They decrease intracellular free calcium concentration and induce myometrial relaxation [2-4].

Nifedipine is the most commonly used drug for preterm labour inhibition at a daily dose of 30-60 mg daily. Randomised controlled trials report a similar tocolytic effect for nifedipine compared with $\beta$ adrenergic receptor agonists [20]. Unfortunately, there is no placebo-controlled studies available to confirm it. A Cochrane Database review metaanalysis published in 2003, reported a decreased number of deliveries within 7 days following treatment and also, a reduced incidence of neonatal respiratory distress syndrome [21]. A recent systematic review based on 26 trials and 2179 patients confirms a higher efficiency and a lower side effects incidence in the nifedipine group compared to $\beta$ adrenergic receptor agonists-treated patients [22]. These data confirm that nifedipine is a efficient tocolytic agent, with an easy oral route of administration, few side effects, and a low neonatal complications rate. However, it should be used with caution in patients with compromised cardiovascular condition as they may be at risk of pulmonary oedema and cardiac failure [5].

3.7. Progesterone and 17- $\alpha$-Hydroxyprogesterone Caproate. Progesterone is a steroid hormone secreted by the corpus luteum and by the placenta after 8 weeks of gestation. It has a physiological effect on uterine quiescence mediated by a direct effect on intracellular calcium concentration and prostaglandin synthesis $[1,2,5,9]$. Several randomised trials reported a significantly reduced incidence of preterm birth in patients at risk treated either with weekly intramuscular $17-\alpha$-hydroxy progesterone caproate [23] or daily vaginal micronized progesterone $[24,25]$ from 24 to 34 weeks. But these treatments showed no benefit in terms of perinatal mortality and morbidity [2, 5, 23-25]. The vaginal route of progesterone administration is associated with less side effects such as sleepiness and headaches $[4,5]$. Although these treatments seem effective in patients with previous history of preterm birth or with a short cervix, it is essential to collect more data in large randomised controlled trials for confirming its potential benefit in the prevention of preterm delivery.

3.8. Antibiotics. Infection is one of causal factors of preterm labour with an incidence of $20-40 \%$, especially before 30 weeks $[1,2]$. Antibiotics use for preventing preterm labour has been largely studied $[5,28-30]$. In the presence of preterm labour with intact membranes, the prophylactic administration of antibiotics is not recommended as there is little evidence of benefits [28]. But if there is a preterm rupture of the membranes (PROM), a meta-analysis based on 22 studies including more than 6000 patients, shows a significant decrease of preterm delivery and chorioamnionitis rate in the treated group [29]. Neonatal complications were also lower in this population $[4,29]$. In bacterial vaginosis associated with pregnancy, antibiotics were found to eradicate infection but they showed no effect on the incidence of preterm delivery [30]. In conclusion, PROM is the only clinically proved indication for using antibiotics in order to prevent preterm birth [29].

\section{Discussion}

There are many possible interventions aiming to treat this multifactorial syndrome called preterm delivery. As described here, only some drugs have been proved to be effective on the contraction process, but there are no clear evidence of associated improved neonatal outcome. Some drugs are used as first-line single therapy such as $\beta$ adrenergic receptor agonists and atosiban in Europe [11, 12]. In severe cases, combined therapy could be offered but should be restricted because of adverse effects addition. A Dutch prospective study based on 1920 women, reported that the overall incidence of severe adverse effect is doubled when a multiple-drug regimen is chosen [27]. The literature review evidences that there are still insufficient data regarding some therapies such as the effectiveness of progesterone in the absence of previous medical history and the role of antibiotics, bed rest, and maintenance therapy $[5,31]$.

Specific conditions are subject to discussion: in multiple pregnancies, expanded blood volume and anaemia may predispose to pulmonary oedema when tocolytic agents such as $\beta$ adrenergic receptor agonists, magnesium sulphate, and calcium channel blockers are prescribed. In these pregnancies, atosiban, with its low side effects incidence, seems to be the safest choice.

The role of tocolysis in PROM allows pregnancy prolongation for corticosteroids administration but has not been reported to significantly improve neonatal outcome [32]. Is long-term therapy effective? There is no clinical evidence on published trials and systematic review to justify tocolytic therapy maintenance except for atosiban [31].

A critical review about tocolysis points to the potential risk of delaying preterm delivery specially in case of infectious or inflammatory process and does not evidence an improved neonatal outcome as tocolysis is often associated with corticosteroids administration [26].

\section{Conclusions}

Prevalence of preterm birth has increased during the last decades and it is a real public health concern. Management with tocolytic drugs aims to stop uterine contractions and to prevent neonatal risks associated with prematurity by in 
TABLE 1: Effects of currently used tocolytic drugs.

\begin{tabular}{|c|c|c|c|c|}
\hline Drugs & Effects & Outcome & Side effects & Studies \\
\hline \multirow[t]{2}{*}{$\beta$ AdRA } & Decrease cAMP & Delay D 2-7 days & Cardiovascular & $\mathrm{RCT}[5,11,12]$ \\
\hline & & & Metabolic & Meta-analysis $[2,10]$ \\
\hline NO donor & Increase cGMP & Delay D 2 days & Cardiovascular & Small series $[2,5]$ \\
\hline \multirow[t]{4}{*}{$\mathrm{MgSO}_{4}$} & Decrease IC Ca++ & No tocolytic effect & Neurological & RCT, meta-analysis \\
\hline & & & Metabolic & {$[2,4-6,13,14]$} \\
\hline & & & Perinatal mortality & \\
\hline & & Fetal neuroprotection & & RCT $[15,16]$ \\
\hline \multirow[t]{3}{*}{ PgSI } & On gap junction & Delay D 2-7 days & Gastrointestinal & RCT, meta-analysis \\
\hline & Decrease IC Ca++ & & Fetal kidney function & {$[2,4-6,17,18,26]$} \\
\hline & & & $\begin{array}{l}\text { Premature closure ductus } \\
\text { arteriosus }\end{array}$ & \\
\hline \multirow[t]{3}{*}{ Ox RA } & $\begin{array}{l}\text { Competition with receptor } \\
\text { binding }\end{array}$ & Controversial efficiency & IUGR? Mortality? & Review [2] \\
\hline & & & Few side effects & RCT, meta-analysis \\
\hline & & & & {$[4,5,9,11,12,19,27]$} \\
\hline \multirow[t]{3}{*}{$\mathrm{Ca}++\mathrm{CB}$} & Decrease IC Ca++ & Delay D 7 days & Cardiovascular & No placebo RCT \\
\hline & & Decreased neonatal mor & & Comparative RCT \\
\hline & & & & {$[2,4,9,20-22]$} \\
\hline \multirow[t]{3}{*}{ Progesterone } & \multicolumn{3}{|c|}{ Reduction preterm delivery in high-risk patients } & RCT $[23,25]$ \\
\hline & Decrease IC Ca++ & & Sedative & \\
\hline & Decrease Pg synthesis & & Liver cytolysis & {$[24,26]$} \\
\hline
\end{tabular}

utero transfer of the pregnant patient in a tertiary specialized centre and by corticosteroids administration $[1,2,7]$.

Our review of several studies and meta-analyses reported on Table 1 confirm the efficacy of $\beta$ adrenergic receptor agonists, prostaglandin-synthetase inhibitors, and atosiban for delaying delivery for 24-48 hours $[2,5,6,10,11,17]$.

In terms of maternal and fetal safety, the overall prevalence of severe side effects associated with tocolysis is around $1 \%$ and is more frequent in multiple therapies, multiple gestation, and preterm rupture of the membranes [27]. Atosiban is our first choice drug for safety, followed by prostaglandin-synthase inhibitors and nifedipine $[2,5,6,12,27]$.

For the future, tocolytic drugs development should aim to reach a better efficacy in terms of pregnancy prolongation and a lower adverse effects profile. A better understanding of the regulation of myometrial contractility and the detection of specific maternal or fetal parameters should be used for new tocolytic strategies. Last generation of oxytocin receptor antagonists such as barusiban could be more efficient and have less affinity for the vasopressin receptors [9]. Specific COX-2 inhibitors or "coxibs," prostaglandin receptors antagonists could be promising tocolytic alternatives [2, 4, 9, 18].

\section{Abbreviations}

$\beta$ AdRA: $\beta$ adrenergic receptor agonist

$\mathrm{MgSO}_{4}$ : Magnesium sulphate

PgSI: $\quad$ Prostaglandin synthase inhibitor

Ox RA: Oxytocin receptor agonist

$\mathrm{Ca}++\mathrm{CB}$ : Calcium channel blocker
Delay D: Delay for delivery

RCT: Randomized controlled trial

DA: Ductus arteriosus

IC Ca++: Intracellular calcium concentration

IUGR: Intrauterine growth retardation.

\section{References}

[1] L. J. Muglia and M. Katz, "The enigma of spontaneous preterm birth," The New England Journal of Medicine, vol. 362, no. 6, pp. 529-535, 2010.

[2] H. N. Simhan and S. N. Caritis, "Prevention of preterm delivery," The New England Journal of Medicine, vol. 357, no. 6, pp. 477-487, 2007.

[3] R. Romero, J. Espinoza, J. P. Kusanovic et al., "The preterm parturition syndrome," BJOG: An International Journal of Obstetrics and Gynaecology, vol. 113, supplement 3, pp. 17-42, 2006.

[4] V. Tsatsaris, D. Cabrol, and B. Carbonne, "Pharmacokinetics of tocolytic agents," Clinical Pharmacokinetics, vol. 43, no. 13, pp. 833-844, 2004.

[5] V. Smith, D. Devane, C. M. Begley, M. Clarke, and S. Higgins, "A systematic review and quality assessment of systematic reviews of randomised trials of interventions for preventing and treating preterm birth," European Journal of Obstetrics and Gynecology and Reproductive Biology, vol. 142, pp. 3-11, 2009.

[6] S. Caritis, "Adverse effects of tocolytic therapy," British Journal of Obstetrics and Gynaecology, vol. 112, supplement 1, pp. 7478, 2005.

[7] J. C. Di Renzo, E. El Saleh, A. Mattei, I. Koutras, and G. Clerici, "Use of tocolytics: what is the benefit of gaining 48 hours for 
the fetus?" BJOG: An International Journal of Obstetrics and Gynaecology, vol. 113, supplement 3, pp. 72-77, 2006.

[8] R. C. Young, "Myocytes, myometrium, and uterine contractions," Annals of the New York Academy of Sciences, vol. 1101, pp. 72-84, 2007.

[9] A. L. Bernal, “The regulation of uterine relaxation," Seminars in Cell and Developmental Biology, vol. 18, no. 3, pp. 340-347, 2007.

[10] S. Anotayanonth, N. V. Subhedar, P. Garner, J. P. Neilson, and S. Harigopal, "Betamimetics for inhibiting preterm labour," Cochrane Database of Systematic Reviews, no. 4, article CD004352, 2004.

[11] Worldwide Atosiban Versus Betaagonists Study Group, "Effectiveness and safety of the oxytocin antagonist atosiban versus beta adrenergic agonists in the treatment of preterm labour," British Journal of Obstetrics and Gynaecology, vol. 108, no. 2, pp. 133-142, 2001.

[12] J. Wex, M. Connolly, and W. Rath, "Atosiban versus betamimetics in the treatment of preterm labour in Germany: an economic evaluation," BMC Pregnancy and Childbirth, vol. 9, article 23, 2009.

[13] C. A. Crowther, J. E. Hiller, and L. W. Doyle, "Magnesium sulphate for preventing preterm birth in threatened preterm labour," Cochrane Database of Systematic Reviews, no. 4, article CD001060, 2002.

[14] R. Mittendorf and P. G. Pryde, "A review of the role for magnesium sulphate in preterm labour," BJOG: An International Journal of Obstetrics and Gynaecology, vol. 112, supplement 1, pp. 84-88, 2005.

[15] C. A. Crowther, J. E. Hiller, L. W. Doyle, and R. R. Haslam, "Effects of magnesium sulphate for preterm neuroprotection before preterm birth," Journal of the American Medical Association, vol. 290, no. 20, pp. 2669-2676, 2003.

[16] S. A. Reeves, R. S. Gibbs, and S. L. Clark, "Magnesium for fetal neuroprotection," American Journal of Obstetrics and Gynecology, vol. 204, pp. 202e1-202e4, 2011.

[17] J. F. King, V. Flenady, S. Cole, and S. Thornton, "Cyclooxygenase (COX) inhibitors for treating preterm labour," Cochrane Database of Systematic Reviews, no. 2, article CD001992, 2005.

[18] R. Savoly, D. Slater, N. M. Fisk, D. K. Edmonds, and P. Bennett, "Use of a cyclo-oxygenase type-2-selective non-steroidal antiinflammatory agent to prevent preterm delivery," The Lancet, vol. 350, no. 9073, pp. 265-266, 1997.

[19] D. Papatsonis, V. Flenady, S. Cole, and H. Liley, "Oxytocin receptor antagonists for inhibiting preterm labour," Cochrane Database of Systematic Reviews, no. 3, article CD004452, 2005.

[20] H. P. Van Geijn, J. E. Lenglet, and A. C. Bolte, "Nifedipine trials: effectiveness and safety aspects," British Journal of Obstetrics and Gynaecology, vol. 112, supplement 1, pp. 79-83, 2005.

[21] J. F. King, V. J. Flenady, D. N. M. Papatsonis, G. A. Dekker, and B. Carbonne, "Calcium channel blockers for inhibiting preterm labour," Cochrane Database of Systematic Reviews, no. 1, article CD002255, 2003.

[22] A. Conde-Agudelo, R. Romero, and J. P. Kusanovic, "Nifedipine in the management of preterm labor: a systematic review and metaanalysis," American Journal of Obstetrics and Gynecology, vol. 204, no. 2, pp. 134.e1-134.e20, 2011.

[23] P. J. Meis, M. Klebanoff, E. Thom et al., "Prevention of recurrent preterm delivery by 17 alpha hydroxyprogesterone caproate," The New England Journal of Medicine, vol. 348, no. 24, pp. 2379-2385, 2003.
[24] E. B. Fonseca, E. Celik, M. Parra, M. Singh, and K. H. Nicolaides, "Progesterone and the risk of preterm birth among women with a short cervix," The New England Journal of Medicine, vol. 357, no. 5, pp. 462-469, 2007.

[25] G. C. Di Renzo, A. Rosati, A. Mattei, M. Gojnic, and S. Gerli, "The changing role of progesterone in preterm labour," BJOG: An International Journal of Obstetrics and Gynaecology, vol. 112, no. 1, pp. 57-60, 2005.

[26] A. P. Kenyon and D. Peebles, "Myth: tocolysis for prevention of pretermbirth has a major role in modern obstetrics," Seminars in Fetal \& Neonatal Medecine, vol. 16, pp. 242-246, 2011.

[27] R. de Heus, B. W. Mol, J. J. H. M. Erwich et al., "Adverse drug reactions to tocolytic treatment for preterm labour: prospective cohort study," BMJ, vol. 338, no. 7697, article b744, 2009.

[28] J. King and V. Flenady, "Prophylactic antibiotics for inhibiting preterm labour with intact membranes," Cochrane Database of Systematic Reviews, no. 4, article CD000246, 2002.

[29] S. Kenyon, M. Boulvain, and J. Neilson, "Antibiotics for preterm rupture of membranes," Cochrane Database of Systematic Reviews, no. 2, article CD001058, 2003.

[30] H. M. MacDonald, P. Brocklehurst, and A. Gordon, "Antibiotics for treating bacterial vaginosis in pregnancy," Cochrane Database of Systematic Reviews, no. 1, article CD000262, 2007.

[31] J. G. Thornton, "Maintenance tocolysis," BJOG: An International Journal of Obstetrics and Gynaecology, vol. 112, no. 1, pp. 118-121, 2005.

[32] H. Helmer, "Frequently asked questions about tocolytics," British Journal of Obstetrics and Gynaecology, vol. 112, supplement 1, pp. 94-96, 2005. 


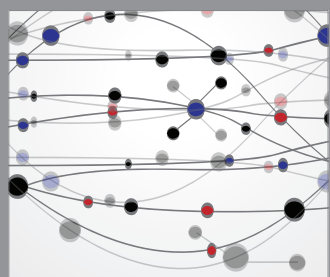

The Scientific World Journal
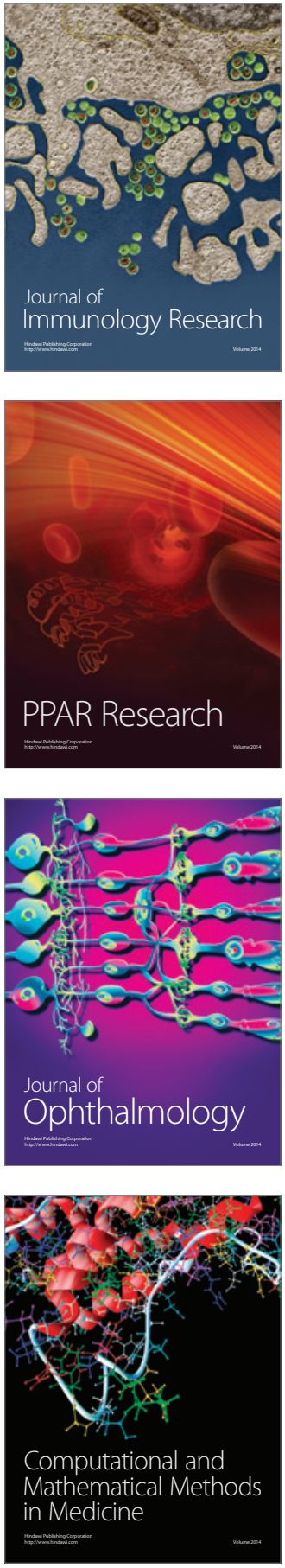

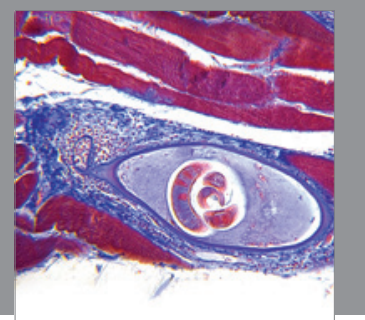

Gastroenterology

Research and Practice
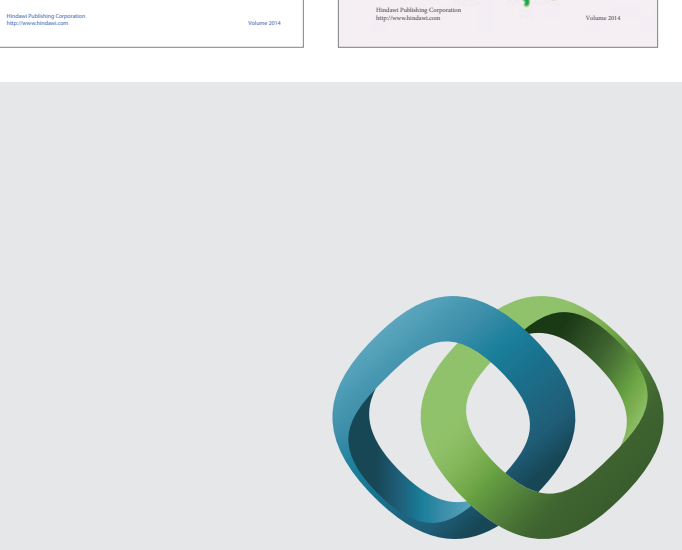

\section{Hindawi}

Submit your manuscripts at

http://www.hindawi.com
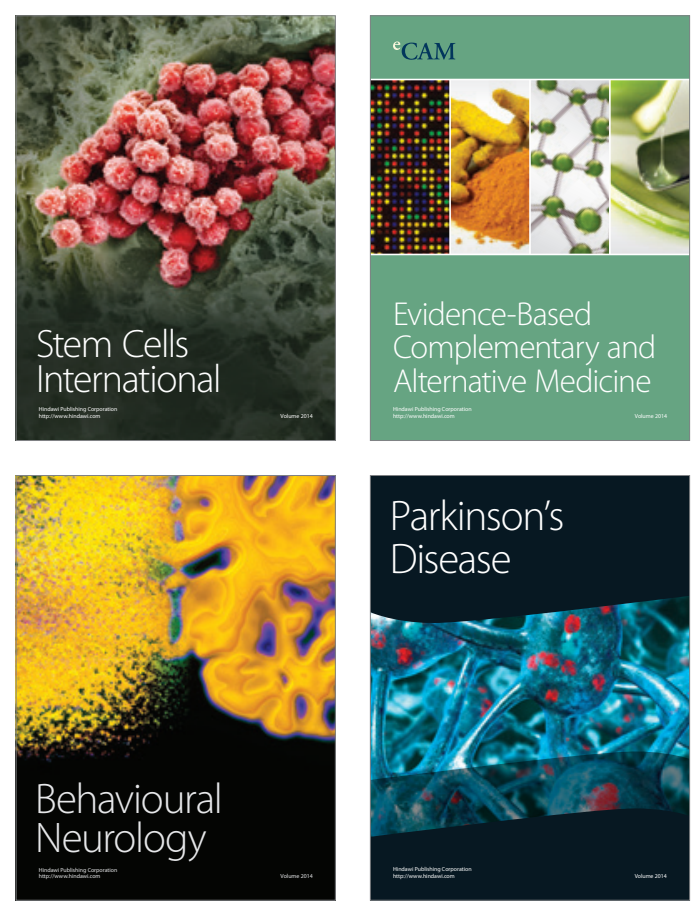

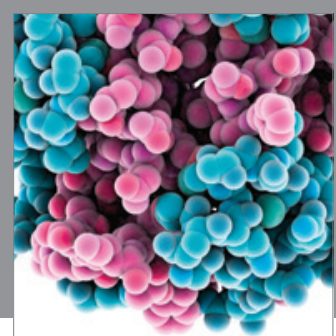

Journal of
Diabetes Research

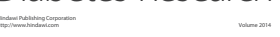

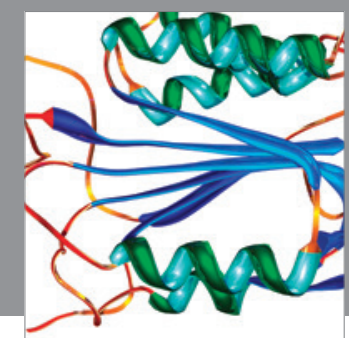

Disease Markers
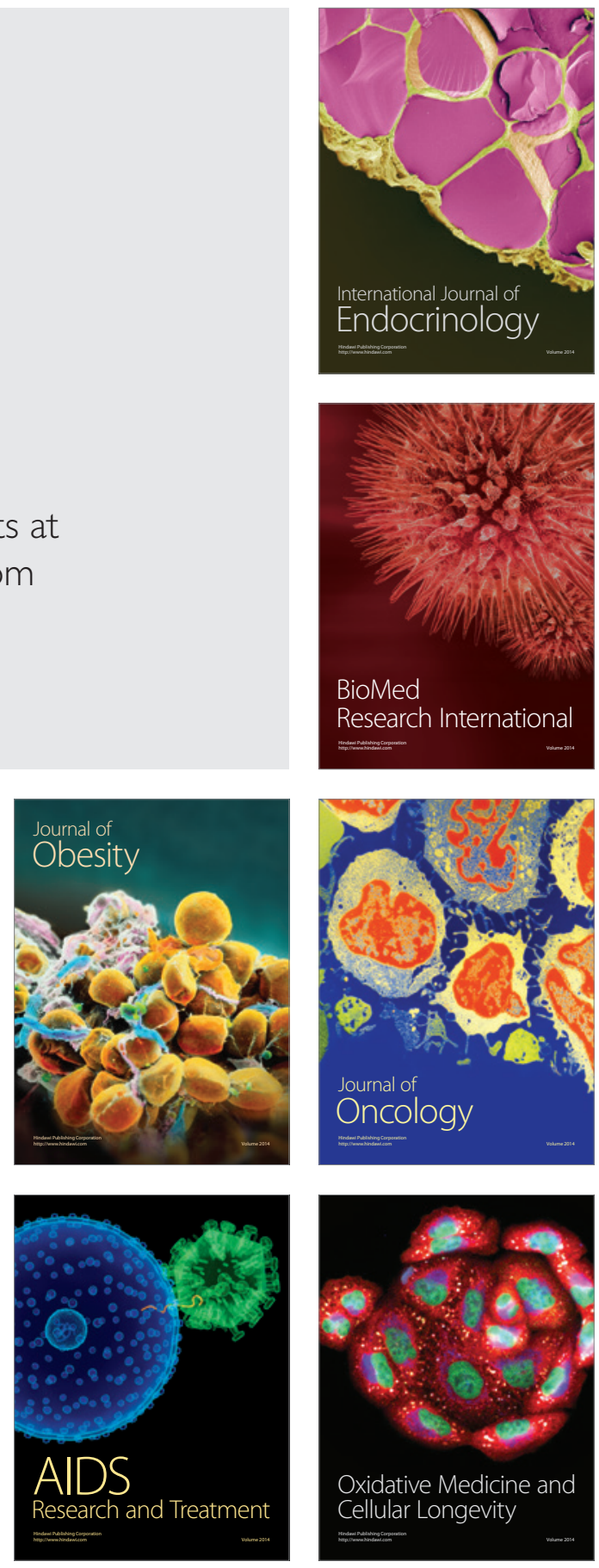